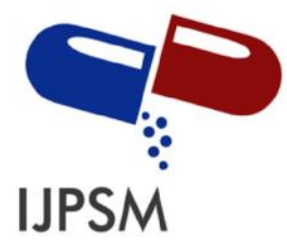

Aquino López Tatiana et al, Int. Journal of Pharmaceutical Sciences and Medicine (IJPSM),

Pharma Middle East Virtual Congress (Dec 07-08, 2020)

www.pharma-middleeast.plenareno.com

ISSN: 2519-9889

Impact Factor: 3.426

\title{
Effect of Hypoxia in the Pharmacological Treatment of Chronic Mountain Sickness (monge sickness) in Native Residents of High Altitude
}

\author{
Aquino López Tatiana (1), Aylas Aylas Lucero (1), Brian Talledo Flores(1), Correa Muñoz(1), Mishel, Loayza Miranda \\ Jesus Alexander(1), Mendoza Chuquillanqui Lenin (1), Mercado Baltazar María de los Angeles(1), Quispe Hidalgo \\ Natalia(1), Quispe Tovar Consuelo Milagros(1), Ramos Lucas Alexa, Soto Pecho Karen(1), Torres Surichaqui Erick (1), \\ Vargas Malpica Jesús(1), Victorino Ramos Kely(1), Zurita Millán Daniela(1), Gamarra Castillo, Fabricio Paul (2) \\ ${ }^{1}$ Human Medicine Faculty, University of Peru Los Andes, Huancayo-Peru \\ ${ }^{2}$ Faculty of Human Medicine, Universidad Peruana Los Andes, Huancayo-Peru
}

DOI: 10.47760/ijpsm.2020.v05i12.004

\begin{abstract}
Introduction: Altitude is a natural medical research laboratory which provides results with important implications for the understanding of diseases that affect millions of people living at altitude, as well as for the treatment of hypoxemia-related diseases in patients living at low altitude. Monge described a disease in the Peruvian Andes that is characterized by excessive polycythemia and congestive symptoms that are dramatically alleviated in the descent to lower levels.
\end{abstract}

Materials and methods: The research is descriptive, non-observational, non-experimental, crosssectional, retrospective. A search was carried out in Pubmed for scientific articles published in both the Andean and South American countries. This search was done in both Spanish and English. The search for scientific articles included all articles that spoke of "mountain sickness", "hypoxia". The main exclusion criteria were articles that did not include information on altitude sickness in South America.

Results: Hemoglobin concentrations and hematocrits of normal native Cerro de Pasco were in the expected range but were found to be much higher in natives with chronic mountain sickness whose artery oxygen saturations of hemoglobin were $59.6,74.2,75.9,78.8$ and $80.0 \%$ or, in contrast to $81 \%$, which is the mean value for that in Morococha (4540 m).

Discussion: To our knowledge, this is the first study to evaluate the effect of ACZ on ventilation and ventilatory control in subjects with CMS. We seek to determine whether chronic carbonic anhydrase inhibition could show similar therapeutic efficacy in chronic hypoxia, as occurs in subjects exposed to acute hypoxia, due to its effects on improving blood oxygenation.

Conclusions: Administration of ACZ provides a beneficial effect on the respiratory function of high-altitude natives with CMS and, therefore, may be an effective therapy for the disease. Defective synthesis of no by the pulmonary endothelium and alveolar epithelium has been shown to be the central event in the pathogenesis of exaggerated hypoxic pulmonary vasoconstriction. 